\title{
Too Many Alternatives: Density, Symmetry and Other Predicaments
}

\author{
Danny Fox \\ Massachusetts Institute of Technology
}

\section{Goal}

In a recent paper, Martin Hackl and I identified a variety of circumstances where scalar implicatures, questions, definite descriptions, and sentences with the focus particle only are absent or unacceptable (Fox and Hackl 2006, henceforth F\&H). We argued that the relevant effect is one of maximization failure (MF): an application of a maximization operator to a set that cannot have the required maximal member. We derived MF from our hypothesis that the set of degrees relevant for the semantics of degree constructions is always dense (the Universal Density of Measurement, UDM).

The goal of this paper is to present an apparent shortcoming of $\mathrm{F} \& \mathrm{H}$ and to argue that it is overcome once certain consequences of the proposal are shown to follow from more general properties of MF. Specifically, the apparent problem comes from evidence that the core generalizations argued for in $\mathrm{F} \& \mathrm{H}$ extend to areas for which an account in terms of density is unavailable. Nevertheless, I will argue that the account could still be right. Certain dense sets contain "too many alternatives" for there to be a maximal member, thus leading to MF. But, there are other sets that lead to the same predicament. My goal will be to characterize a general signature of MF in the hope that it could be used to determine the identity of alternatives in areas where their identity is not clear on independent grounds.

\section{The Proposal in F\&H}

Before I can discuss the apparent problem for F\&H, I need to go over the basics of the proposal. The relevant phenomena investigated involve degree constructions in which MF is predicted by the UDM stated in (1).

(1) The Universal Density of Measurements (UDM): Measurement Scales that are needed for Natural Language Semantics are formally dense.

\subsection{A Constraint on Implicatures and only:}

Special thanks goes to Márta Abrusán, Gennaro Chierchia, Nathan Klinedinst, Philippe Schlenker, and Benjamin Spector for numerous discussions of the ideas presented in this paper. I would also like to thank Emmanuel Chemla, Kai von Fintel, Martin Hackl, and Ede Zimmermann for helpful comments. Finally, I'm grateful to the MIT-France Seed Fund Grant for Collaborative Research on Presuppositions and Implicatures (2006-2007) 
Here I will review some consequences of the UDM for the focus sensitive operator only and for the covert operator responsible for the computation of scalar implicatures, exh. (For the proposal that exh is crucial for the computation of scalar Implicatures, see, among others, Groenendijk and Stokhof 1984, Sevi 2005, Fox 2007 , and Chierchia, Fox and Spector, in progress.)

\subsubsection{The UDM and Intuitively Dense Scales}

Consider the simple, and rather unsurprising, case of MF exemplified in (2), which I call here the basic effect.

\section{THE BASIC EFFECT}

a. John weighs more than 150 pounds. *Implicature: John weighs exactly $\mathrm{S}(150)$ pounds, where $\mathrm{S}$ is the successor function.

b. John weighs very little. ${ }^{*} \mathrm{He}$ only weighs more than $150_{\mathrm{F}}$.

(2a) cannot have the implicature that 150 is largest degree such that John's weight is greater than that degree, i.e., the implicature that John's weight is exactly $S(150)$ lbs, where $S(150)$ is the successor of 150 (say, 151). Similarly, an attempt to state the implicature explicitly using the focus particle only in (2b) leads to unacceptability. This is unsurprising since it is unclear what the successor of 150 ought to be. (Any choice, e.g. 151 or 150.5 , seems completely arbitrary.)

Under the UDM, this rather unsurprising fact receives a very specific characterization: 150 (like other degrees) has no successor; consequently (2b) can have no coherent meaning, and (2a) can have no implicature. Stated somewhat differently, if John's weight is exactly $\mathrm{d}$ lbs where $\mathrm{d}>150$, it follows from the UDM that there is a degree d', s.t. $150<\mathrm{d}^{\prime}<\mathrm{d}$. Since John's weight is greater than $\mathrm{d}^{\prime},(2 \mathrm{~b})$ is contradictory, hence unacceptable, and, since $(2 \mathrm{~b})$ is the implicature that would normally be associated with (2a), the implicature is unavailable.

Consider, now, what happens when the sentences in (2) are embedded under universal modal operators. As illustrated in (3), the sentences no longer suffer from MF. ${ }^{1}$

\section{Universal Modals Circumvent the Problem}

a. John is required to weigh more than 150 pounds (if he wants to participate in this fight).

Implicature: There is no degree greater than $150, d$, s.t. John is required to weigh more than d pounds.

b. John is only required to weigh more than $150_{\mathrm{F}}$ pounds.

(3a), in contrast to (2a), has an implicature, and (3b), in contrast to (2b), is an acceptable sentence. This contrast is expected under the UDM: although there can be no maximal degree such that John's weight exceeds that degree (for the reasons I just mentioned), there can be a maximal degree such that a certain set of requirements determine that John's weight ought to exceed that degree. This is the

\footnotetext{
${ }^{1}$ The same predictions hold for quantifiers over individuals, as discussed in $\mathrm{F} \& \mathrm{H}$, given that no constraints of logic block the domain of individuals from being very large.
} 
case, for example, if a requirement that John's weight exceed the relevant degree is the only existing requirement.

Universal modals can circumvent the MF effect predicted by the UDM. However, existential modals cannot. We thus predict that (4) will pattern with (2) rather than (3).

\section{Existential Modals Do Not Circumvent the Problem}

a. John is allowed to weigh more than 150 pounds (and still participate in this fight).

*Implicature: There is no degree greater than 150 , d, s.t. John is allowed to weigh more than $\mathrm{d}$ pounds.

b. *John is only allowed to weigh more than $150_{\mathrm{F}}$ pounds.

To see that this is predicted by the UDM, assume that John is allowed to weigh more than $150 \mathrm{lbs}$, i.e., that there is a possible world, w, consistent with the relevant rules, in which John weighs more than $150 \mathrm{lbs}$. Given our discussion of (2), there is a degree d greater than 150 such that, in w, John weighs more than $d$ lbs. Since w is consistent with the rules, John is allowed to weigh more than d lbs, and 150 is not the maximal degree that the rules allow John's weight to exceed. In other words, $(4 \mathrm{~b})$ is contradictory, hence unacceptable. Since this contradiction is the meaning of the potential implicature of $(4 a)$, there can be no implicature.

\subsubsection{Density as a Formal Property}

The pattern we've seen in (2-4) is replicated in (5-7). One would, therefore, hope that the account provided for (2-4) could be extended.

\section{THE BASIC EFFECT}

a. John has more than 3 children. *Implicature: John has exactly 4 children. (Krifka 1999)

b. John has very few children. *He only has more than THREE.

\section{Universal Modals Circumvent the Problem}

a. You're required to read more than 30 books. Implicature: There is no degree greater than 30 , d, s.t. you are required to read more than $\mathrm{d}$ books.

b. You're only required to read more than $30_{\mathrm{F}}$ books.

\section{EXISTENTIAL MODALS Do NoT}

a. You're allowed to smoke more than 30 cigarettes.

*Implicature: There is no degree greater than 30 , d, s.t. you are allowed to smoke more than d cigarettes.

b. *You're only allowed to smoke more than $30_{\mathrm{F}}$ cigarettes.

This extension, however, is possible only if density is assumed to apply to all degree domains, even those that are not intuitively dense. This assumption is the essence of the UDM: 
(8) The Universal Density of Measurements (UDM): Measurement Scales that are needed for Natural Language Semantics are formally dense.

a. The Intuitive Consequence: Scales of height, size, speed, and the like are dense.

b. The Radical Consequence: All Scales are dense; cardinality is not a concept of Natural Language Semantics.

\subsection{A Constraint on Questions and Definite Descriptions (Negative Islands)}

Similar consequences are shown in $\mathrm{F} \& \mathrm{H}$ to hold for questions and definite descriptions. Specifically, certain negative island follows as a Maximization Failure, with obviation predicted by an appropriate quantifier.

\subsubsection{Density as an Intuitive Property of Scales}

Consider the negative island exemplified in (9). Although less obvious than what we've seen in (2), this also turns out to be a basic case of MF, once plausible assumptions about questions and definite descriptions are taken into account.

\section{THE BASIC EFFECT}

a. *How much does John not weigh? (Obenauer, Rizzi., Rullmann, passim)

What is the successor of John's weight (the minimal amount $d$, such that he doesn't weigh d much)?

b. *I have the amount of water that you don't. cf. I have the amount of water that you do. I have an amount of water that you don't.

Suppose that John weighs exactly $200 \mathrm{lbs}$. The Karttunen denotation of (9) - the set of true answers to the question - contains all propositions of the form John does not weigh $d \mathrm{Ibs}$, where $\mathrm{d}$ is greater than 200. It is easy to see that these propositions are more informative the smaller $\mathrm{d}$ is, and that, under the UDM, there is no proposition in the set that entails all others. If we assume, with Dayal (1996), that a question presupposes that a member of its Karttunen denotation entails all others, the unacceptability of $(9 a)$ is accounted for as a presupposition failure. This account extends immediately to (9b), if the maximality presupposition of definite descriptions is defined with reference to entailment. ${ }^{2}$

Consider, now, what happens when a universal modal is added to expressions such as those in (9) directly above negation (or equivalently an existential modal directly below negation). As illustrated in (10), the resulting expressions no longer suffer from MF.

\footnotetext{
${ }^{2} \mathrm{~F} \& \mathrm{H}$ follow von Fintel, Fox, and Iatridou, who present evidence that the definite article denotes a function from properties $\mathrm{P}$ to partial individual concepts, defined for a world $\mathrm{w}$, only if there is a most informative individual in the extension of the property, i.e., if $\exists x[P(x)(w)=1 \& \forall y$ $[\mathrm{P}(\mathrm{y})(\mathrm{w})=1 \rightarrow[\mathrm{P}(\mathrm{x})$ entails $\mathrm{P}(\mathrm{y})]]]$. See $(17 \mathrm{~d})$, below.
} 


\section{Universal Modals Circumvent the Problem}

a. How much are you sure that this vessel won't weigh?

b. How much radiation are we not allowed to expose our workers to?

c. The amount of radiation that we are not allowed to expose our workers to is greater than we had thought.

d. The amount of money that you are sure that this stock will never sell for is quite high. (Are you sure that your estimation is correct.)

The contrast between (9) and (10) follows from the UDM: although there can be no minimal degree such that the vessels weighs less than that degree (i.e. a minimal degree, d, s.t. the vessel doesn't weigh d), there can be a minimal degree such that a certain set of beliefs determine that the vessel's weight is less than that degree. This is the case, for example, if a belief that the vessel's weight is below the relevant degree is the only existing belief.

Once again, we predict a contrast between universal and existential modals:

\section{(11) Existential Modals do Not Circumvent The Problem}

a. How much radiation is the company not allowed to expose its workers to?

b. *How much rice is the company not required to give its workers? ${ }^{3}$

To see that this is predicted, assume that the relevant company is not required to give its workers a particular amount of rice, say $5 \mathrm{lbs}$. This means that there is a possible world, w, consistent with the relevant rules in which the company gives its workers less that $5 \mathrm{lbs}$ of rice, say $4.9 \mathrm{lbs}$. Given the UDM, there is a degree $\mathrm{d}$ between 4.9 and 5, say 4.95. Since the company did not give its workers $4.95 \mathrm{lbs}$ of rice in $\mathrm{w}$, and since $\mathrm{w}$ is consistent with the rules, the company is not required to give its works $4.95 \mathrm{lbs}$ of rice, and 5 is, therefore, not the minimal degree such that the rules do not require the company to give its workers an amount of rice to that degree. In other words, the presupposition of (11b) cannot be met.

\subsubsection{Density as a Formal Property}

The pattern we've seen in (9-11) is replicated in (12-14):

\section{THE BASIC EFFECT}

*How many kids do you not have?

\section{(13) Universal Modals Circumvent the Problem}

a. If you live in China, how many children are you not allowed to have?

b. How many days a week are you not allowed to work (according to union regulations)?

\footnotetext{
${ }^{3}$ Ignore the following irrelevant reading: what is the amount of food such that there is food in that amount and the company is not required to give that food to its workers?. Such a reading is not available in the following:

(i) (When you enter the country) How much money are you not allowed to have?

(ii) $\quad *$ (When you enter the country) How much money are you not required to have?
} 
c. How many soldiers is it (absolutely) certain that the enemy doesn't have?

\section{EXISTENTIAL MODALS Do Not}

a. *If you live in Sweden, how many children are you not required to have?

b. *How many days a week are you not required to work (even according to the company's regulations)?

c. *How many soldiers is it possible that the enemy doesn't have?

Once, again, the explanation can be extended only if density is assumed for all degree domains, as the UDM dictates.

\subsection{The Generalization}

The observation made in the previous two subsections could all be viewed as a direct consequence of the logical traits of degree properties of a particular sort, $\mathrm{N}$ (ecessarily)-open properties. We call a property of degrees, $\varphi$ (type $\langle\mathrm{d}, \mathrm{st}\rangle)$, an $N$-open property if, for every degree, $\mathrm{d}$, such that $\varphi(\mathrm{d})$ is true in some world $\mathrm{w}$ $(\varphi(d)(w)=1)$, there is necessarily another degree $d^{\prime}$, such that $\varphi\left(d^{\prime}\right)(w)=1$ and $\varphi\left(d^{\prime}\right)$ is a more informative proposition than $\varphi(d)$. (Under such circumstances, we will say that $d^{\prime}$ is a more informative degree than $d$, given $\varphi$. When $\varphi$ 's identity is obvious from the surrounding context, I might simply say that $\mathrm{d}^{\prime}$ is more informative than d.)

$$
\begin{aligned}
& \text { We call } \varphi_{<\mathrm{d}, \mathrm{st}>} \text { an } N \text {-open property if: } \\
& \quad \forall \mathrm{w}, \mathrm{d}[(\varphi(\mathrm{d})(\mathrm{w})=1) \rightarrow \\
& \quad \exists \mathrm{d}^{\prime}\left[\left(\varphi\left(\mathrm{d}^{\prime}\right)(\mathrm{w})=1 \& \varphi\left(\mathrm{d}^{\prime}\right) \text { asymmetrically entails } \varphi(\mathrm{d})\right]\right]
\end{aligned}
$$

In the previous two subsections we looked at various properties of degrees that, under the UDM, are N-open properties. In Section 2.1.1., we focused on properties such as that which is true of a degree if John weighs more (in lbs) than that degree ( $\lambda d$. $\lambda w$. John weighs more than $d$ in $w)$. Given the UDM, there is no world, w, s.t. there is a maximal degree $\mathrm{d}$ of which the property is true in w (i.e., no maximal degree $d$ such that John weighs more than $d$ in w). Since for this property larger degrees are more informative than smaller degrees (the property is upward monotone), we conclude that the property is N-open. In Section 2.1.2., we focused on upward monotone properties such as $\lambda d$. $\lambda w$. John has more than $d$ children in $w$. These properties are likewise $\mathrm{N}$-open if the radical consequence of the UDM in $(8 b)$ is correct.

In Section 2.2.1., we focused on properties such as that which is true of a degree if John's weight does not reach that degree $(\lambda d$. $\lambda w$. John does not weigh $d$ in $w$ ). Given the UDM, there is no world, w, s.t. there is a minimal degree $\mathrm{d}$ of which the property is true in w (i.e., no minimal degree $d$ such that John does not 
weigh $d$ in w). Since for this property smaller degrees are more informative than bigger degrees (the property is downward monotone), we conclude that the property is N-open. In Section 2.2.2., we focused on downward monotone properties such as $\lambda d$. $\lambda w$. John has more than d children in $w$. These properties are $\mathrm{N}$-open if the radical consequence of the UDM in (8b) is correct.

We then made various predictions that followed from the logical traits of $\mathrm{N}$-open properties. The most direct logical property is that MF would result whenever a particular operator, $\mathrm{MAX}_{\mathrm{inf}}$, applies to an $\mathrm{N}$-open property:

(16) Constraint on Interval Maximization (CIM): N-open properties cannot be maximized by $\mathrm{MAX}_{\text {inf. }}$

$$
\begin{aligned}
\operatorname{MAX}_{\text {inf }}\left(\varphi_{<\alpha, \mathrm{st}>}\right)(\mathrm{w})= & \text { the } \mathrm{x} \in \mathrm{D}_{\alpha}, \text { s.t., } \varphi(\mathrm{x})(\mathrm{w})=1 \text { and } \\
& \forall \mathrm{y}(\varphi(\mathrm{y})(\mathrm{w})=1 \rightarrow \varphi(\mathrm{x}) \text { entails } \varphi(\mathrm{y}))
\end{aligned}
$$

This constraint, which we take to be a truism, derived the Basic Effect discussed in (2), (5), (9), and (12) under the UDM. To see this, it suffices to observe that natural language operators relevant for sentences with only and scalar Implicatures ( 2 and 5) as well as questions and definite descriptions ( 9 and 12) are defined with crucial reference to $\mathrm{MAX}_{\mathrm{inf}}{ }^{4}$
Lexical Entries 5
a. $\quad \llbracket \operatorname{exh} \rrbracket(\varphi)(d)(w) \Leftrightarrow d=\operatorname{MAX}_{\text {inf }}(\varphi)(w)$.
b. $\llbracket o n l y \rrbracket(\varphi)(d)(w) \Leftrightarrow d=\operatorname{MAX}_{\text {inf }}(\varphi)(w)$, when defined.
c. $\llbracket ? \rrbracket\left(\varphi_{\alpha, \mathrm{st}}\right)=\lambda \mathrm{w}: \exists \mathrm{d}\left[\mathrm{d}=\operatorname{MAX}_{\mathrm{inf}}(\varphi)(\mathrm{w})\right] .\left\{\varphi(\mathrm{x}): \mathrm{x} \in \mathrm{D}_{\alpha}\right\}$
d. 【the $\rrbracket(\varphi)(w)=\operatorname{MAX}_{\text {inf }}(\varphi)(w)$
(von Fintel, Fox, Iatridou)

The Basic Effect in (2), (5), (9), and (12), is derived from (16) and (18) and can be summarized as follows:

\footnotetext{
${ }^{4}$ Ede Zimmerman (p.c.) asked under what notion of content the proposition that John has more than 3.5 children will be logically stronger than the proposition that he has more than 3 children. The relevant notion should not take into account the meaning of the non-logical vocabulary, for example, one could take a diagnolization of the Kaplanian character of a logical form in which all elements of the non-logical vocabulary received an indexical interpretation. See F\&H for a different perspective.

${ }^{5}$ The lexical entries for only and exh in (18) presuppose a movement theory of association with focus (or scalar alternatives by analogy). In the next section, I move to a Roothian theory of association with focus: only and exh take a proposition $\mathrm{p}$ and a set of alternatives A (usually the focus value of the "prejacent"). The Roothian statements translate in an obvious way to (18a,b) as long as $[\mathrm{p}=\varphi(\mathrm{d})] \& \forall \mathrm{q} \in \mathrm{A}[\exists \mathrm{d}[\mathrm{q}=\varphi(\mathrm{y})] \& \forall \mathrm{d}[\exists \mathrm{q} \in \mathrm{A}[\mathrm{q}=\varphi(\mathrm{y})]$. Under such circumstances, $\operatorname{only}_{\text {Roothian }}(\mathrm{A})(\mathrm{p})=\operatorname{only}(\varphi)(\mathrm{x})$.
} 
(19) Basic Consequence: If $\varphi$ expresses an N-open monotone property of degrees, then the following should be unacceptable. ${ }^{6}$
a. $* \operatorname{exh}(\varphi)(\mathrm{d})$
b. *only $(\varphi)(d)$
c. ${ }^{*} \mathrm{wh}_{\mathrm{d}}(\varphi)$
d. *the $(\varphi)$

We can now derive the fact that universal modals circumvent the problem $(3,6$, 10 , and 13) by observing the logical fact in (20), with its empirical consequences in (21).

(20) A universal modal can close an interval:

If $\varphi$ is an $\mathrm{N}$-open monotone property of degrees, $[\lambda \mathrm{d} . \quad \varphi(\mathrm{d})]$ is not.

Proof: Let the modal base for $\quad$ in $\mathrm{w}^{0}$ be $\left\{\mathrm{w}: \varphi\left(\mathrm{d}^{*}\right)(\mathrm{w})=1\right\}$. It is now easy to see that $\operatorname{MAX}_{\text {inf }}([\lambda d . \quad \varphi(d)])\left(w^{0}\right)=d^{*}$.

(21) Consequence for universal modals: A universal modal can close an interval; hence even if $\varphi$ is an N-open monotone property of degrees, the following should be acceptable
a. $\quad$ exh $([\lambda \mathrm{d} . \quad \varphi(\mathrm{d})])\left(\mathrm{d}^{\prime}\right)$
b. only $([\lambda d . \quad \varphi(d)])\left(d^{\prime}\right)$
c. $\operatorname{wh}_{\mathrm{d}}\left(\left[\begin{array}{ll}\lambda \mathrm{d} & \varphi(\mathrm{d})\end{array}\right]\right)$
d. the $([\lambda d . \quad \varphi(d)])$

We can also derive the fact that existential modals cannot circumvent the problem (4, 7, 11 and 14) by observing the logical fact in (22), with its empirical consequences in (23).

(22) An existential modal cannot close an interval:

If $\varphi$ is an N-open monotone property of degrees, so is $[\lambda \mathrm{d} . \diamond \varphi(\mathrm{d})]$.

Proof: Assume otherwise, and let $\operatorname{MAX}_{\text {inf }}([\lambda \mathrm{d} . \diamond \varphi(\mathrm{d})])\left(\mathrm{w}^{0}\right)=\mathrm{d}^{*}$.

$\diamond \varphi\left(\mathrm{d}^{*}\right)$ is true in $\mathrm{w}^{0}$. Hence,

There is a world, $\mathrm{w}^{*} \in \mathrm{MB}_{\mathrm{w} 0}(\diamond)$, s.t. $\varphi\left(\mathrm{d}^{*}\right)\left(\mathrm{w}^{*}\right)=1$.

Since $\varphi$ is N-open, there is a degree $\mathrm{d}^{* *}$, s.t. $\left[\left(\varphi\left(\mathrm{d}^{* *}\right)\left(\mathrm{w}^{*}\right)=1 \&\right.\right.$ $\varphi\left(\mathrm{d}^{* *}\right)$ asymmetrically entails $\left.\varphi\left(\mathrm{d}^{*}\right)\right]$, Hence, $\left[\diamond\left(\varphi\left(\mathrm{d}^{* *}\right)\right)\right]\left(\mathrm{w}^{0}\right)=1$ and $\mathrm{d}^{*} \neq \operatorname{MAX}_{\text {inf }}([\lambda \mathrm{d} . \diamond \varphi(\mathrm{d})])\left(\mathrm{w}^{0}\right)$.

\footnotetext{
${ }^{6}$ In Fox (2007), I argued for a contradiction-free meaning of exh and only (weaker than that of Groenendijk and Stokhof). These arguments are not in conflict with F\&H; in all relevant cases where exhaustification leads to contradictions under (18), it would be vacuous under my definition. See appendix for details.
} 
(23) Consequence for existential modals: An existential modal cannot close an interval. Hence, if $\varphi$ is an N-open monotone property of degrees, then the following should be unacceptable
a. *exh $([\lambda \mathrm{d} . \nabla \varphi(\mathrm{d})])\left(\mathrm{d}^{\prime}\right)$
b. *only $([\lambda \mathrm{d} . \diamond \varphi(\mathrm{d})])\left(\mathrm{d}^{\prime}\right)$
c. ${ }^{*} \mathrm{wh}_{\mathrm{d}}([\lambda \mathrm{d} . \diamond \varphi(\mathrm{d})])$
d. *the $([\lambda \mathrm{d} . \diamond \varphi(\mathrm{d})])$

The fact that the CIM plays an explanatory role in accounting for the status of expressions in natural language can be taken as evidence that natural language has $\mathrm{N}$-open properties, i.e. for The Intuitive Claim, (8a). The fact that the CIM seems to be at work in all degree constructions (even those that putatively make reference to cardinality) constitutes our argument for the universality of the UDM, i.e. for The Radical Claim, (8b).

This was a rather condensed summary of F\&H. For further details, and subtle consequences for the relationship between syntax, semantics, and pragmatics, I will have to refer the reader to the original. My goal here will be to discuss a generalization that was not noticed in $\mathrm{F} \& \mathrm{H}$. We will see that the pattern observed by $\mathrm{F} \& \mathrm{H}$ (obviation by universal quantifiers, and not by existential quantifiers) is expected whenever MF holds, independently of the underlying account of MF. This observation is not problematic for the F\&H account, but does raise the possibility that $\mathrm{MF}$ has sources that are unrelated to density. Nevertheless, I will suggest that the UDM is a better hypothesis than the existing alternative. Furthermore, I will point out other areas where the signature of MF can be spotted, and will entertain speculations pertaining to the nature of the alternatives that are responsible for the effect.

\section{Evidence of a Missed Generalization ${ }^{7}$}

Our account of MF in comparative constructions - e.g. the lack of a Scalar Implicature in (5a), repeated here as (24) - was based on our claim that the argument of $\mathrm{Max}_{\text {inf }}$ in such constructions is an N-open property, a claim that, in turn, followed from the UDM.

(24) John has more than 3 children.

*Implicature: John has exactly 4 children.

$\mathrm{N}$-open property: $\lambda d . \lambda w$. John has more than $d$ children in $w$.

This account, however, cannot extend to (25), which appears to raise the same puzzle, i.e., the lack of an otherwise expected Scalar Implicature.

\footnotetext{
${ }^{7}$ The pattern reported in this section was pointed out to Martin Hackl and me by Gennaro Chierchia, Nathan Klinedinst, Philippe Schlenker, and Benjamin Spector.
} 
John has 4 or more children.

*Implicature: John has exactly 4 children.

Not an N-open property: $\lambda d . \lambda w$. John has $d$ or more children in $w$.

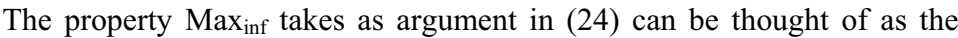
result of abstracting over the position occupied by the scalar item (see note 5). This property is N-open under the UDM. However the parallel property in (25) is not N-open, not even under the UDM. All things being equal, (25) is incorrectly predicted to have the implicature that John has exactly 4 children.

Furthermore, there is some evidence that a unified account for the missing implicatures in (24) and (25) is called for. Specifically, it seems to be the case that the pattern observed in F\&H, which we reviewed in Section 2.1., extends to (25) in its entirety. This seems to hold for all constructions in which a sentence $p$ with an implicature $\neg \mathrm{q}$ is connected to $\mathrm{q}$ by disjunction, a construction for which density seems to be irrelevant.

\section{THE BASIC EFFECT}

a. John has 3 or more children. *Implicature: John has exactly 4 children.

b. John has very few children. *He only has 3 or MORE.

c. John talked to Mary or Sue, or both. *Implicature: John didn't talk to both Mary and Sue.

\section{Universal Modals Circumvent the Problem}

a. You're required to read 30 books or more. Implicature: There is no degree greater than 30 , d, s.t. you are required to read more than $\mathrm{d}$ books.

b. You're only required to read 30 books or MORE.

b'. You're only required to read 30 or MORE books.

c. John is required to talk to Mary or Sue, both. Implicature: John is not required to talk to both Mary and Sue.

\section{(28) Existential Modals Do Not}

a. You're allowed to smoke 30 cigarettes or more. *Implicature: There is no degree greater than 30 , d, s.t. you are allowed to smoke more than d cigarettes.

b. *You're only allowed to smoke more than $30_{\mathrm{F}}$ cigarettes.

c. John is allowed to talk to Mary or Sue, both. *Implicature: John is not allowed to talk to both Mary and Sue.

If the account of the missing implicatures in (24) and (25) is to be identical, it doesn't seem that the UDM can be relevant. Is there an alternative, then? 


\section{Hurford's Generalization and Symmetric Alternatives}

It turns out that there is a very natural way to account for the pattern observed in (26-28). ${ }^{8}$ The account is based on the analysis of a puzzling property of the relevant disjunctions noted in Hurford (1974), and Gazdar (1979). Recall that the pattern in (26-28) holds for all constructions in which a sentence $p$ with an implicature $\neg \mathrm{q}$ is connected to $\mathrm{q}$ by disjunction. Such disjunctions raise an apparently independent problem, namely they appear to violate a constraint on disjunction identified by Hurford (1974). We will see that the solution to this problem proposed by Hurford (with a particular modification designed to deal with Gazdar's observations) explains the pattern in (26-28).

Hurford observes that under normal circumstances a disjunction $A$ or $B$ is infelicitous when B entails A (henceforth, Hurford's Generalization, HG). ${ }^{9}$
a. ??John is an American or a Californian.
b. ??I was born in France or Paris.

$\mathrm{He}$, then, pointed out that his generalization seems to be violated in (30).

I will apply to Cornell or UMASS, or to both.

Structure which violates $\mathrm{HG}:(\mathrm{C} \vee \mathrm{U}) \vee(\mathrm{C} \wedge \mathrm{U})$

In (30), the first disjunct (apparently itself a disjunction: I will apply to Cornell or UMASS, $\mathrm{C} \vee \mathrm{U})$ ) is entailed by the second disjunct (the conjunction $\mathrm{C} \wedge \mathrm{U}$ ). Nevertheless, the sentence is acceptable, and thus appears to counterexemplify HG.

In order to avoid analyzing (30) as a counterexample, Hurford suggested that natural language disjunction is ambiguous between an inclusive disjunction, $\checkmark$, and an exclusive disjunction, $\nabla$. If this is the case, the first disjunct of (30) can be parsed as an exclusive disjunction, $\mathrm{C} \nabla \mathrm{U}$ (as in $30^{\prime}$ ). This exclusive disjunction is false when both of the disjuncts are true, and, thus, is not entailed by the conjunction in the second disjunct.

(30)' Structure which does not violate HG:

$[(\mathrm{C} \nabla \mathrm{U})] \vee(\mathrm{C} \wedge \mathrm{U})$

Gazdar (1979) pointed out that HG is obviated in all constructions in which a sentence $\mathrm{p}$ with an implicature $\neg \mathrm{q}$ is connected to $\mathrm{q}$ by disjunction, i.e.,

\footnotetext{
${ }^{8}$ The account was formulated in Spector (2005), with certain components developed independently in Fox (2004), and some supporting evidence generated in a seminar that I taught together with Gennaro Chierchia in the fall of 2006. For a detailed exposition, see Chierchia, Fox and Spector (in progress). See also Singh (2006).

${ }^{9}$ Also when A entails B, though this is irrelevant for our purposes (but see Singh 2006). See also Simons (2000).
} 
in the disjunctions we've looked at in the previous section, or in examples such as (31). ${ }^{10}$

(31) a. I will do some of the homework or all of it.

b. John read two books or more.

In order to extend Hurford's account of (30) to these cases, we will have to assume that natural language has exclusive some and exclusive two, in addition to exclusive or. For this to follow from a general proposal, we will assume that the relevant exclusive interpretations are derived with the specialized operator that we have been calling exh. (30)' would thus be a shorthand for the structure in (30)", and, likewise, (31) would have the structures in (31)'.

(30)" [Exh $(\mathrm{C}$ or $\mathrm{U})]$ or $[\mathrm{C}$ and $\mathrm{U}]$

(31)' a. [Exh(I will do some of the homework)] or [I will do all of the homework].

b. [Exh(John read two books)] or [John read more than two books]

These structures - with exh within the first disjunct - are forced by HG. ${ }^{11}$ Can this fact help us account for the effect in (26-28)? We will see that it can, once we look at the way scalar implicatures are computed in disjunctive sentences. Consider a simple disjunctive sentence such as that in (32). This sentence does not have the implicature that John didn't talk to Mary nor the implicature that he didn't talk to Sue, even though an utterance of each of the disjuncts would be more informative than the utterance of the disjunction.

\section{(32) THE BASIC EFFECT}

John talked to Mary or Sue.

*Implicature: John didn't talk to Mary.

*Implicature: John didn't talk to Sue.

One possible account for this Basic Effect is based on the fact that scalar implicatures are only generated when a more informative sentence is a member of the set of formal alternative that enter into implicature computation. One might thus postulate that the formal alternatives to a disjunctive sentence do not include

\footnotetext{
${ }^{10}$ Gazdar proposed a weakening of the generalization, a proposal that I do not adopt here. See Chierchia, Fox and Spector for discussion.

${ }^{11}$ The following sentence constructed together with Gennaro Chierchia provides a further argument for this line of reasoning:

It's either the case that each of the kids did some of the homework or that John did all of it and every other kid did just some of it.

In the first disjunct of this sentence, Exh would have appear below the universal quantifier for Hurford's constraint to be satisfied. This seems to be a good result since the sentence is false/odd if there is a kid other than John who did all of the homework. The sentence, thus, provides independent evidence for Hurford's constraint. See Cheirchia, Fox and Spector for further discussion.
} 
the disjuncts. So, although each of the disjuncts is more informative than the disjunction, this fact would not end up yielding a scalar implicature.

But, as Sauerland (2004) points out, it is also possible to claim that each of the disjuncts is an alternative to the disjunction (and preferable on independent grounds). ${ }^{12}$ Under this assumption, the scalar implicature that each of the disjuncts is false is not generated since such an implicature would contradict the utterance of the disjunction, or in other words, would result in MF. ${ }^{13}$

Evidence in favor of the latter possibility comes from the fact that universal modals Circumvent the Problem. (See Sauerland 2005, Spector 2005, and Fox 2007.)

\section{Universal Modals Circumvent the Problem}

John is required to talk to Mary or Sue.

Implicature: John is not required to talk to Mary.

Implicature: John is not required to talk to Sue.

If the disjunction, $p \vee q$ has $p$ and $q$ as alternatives, then, $(p \vee q)$ has $p$ and $q$ as alternatives. ${ }^{14}$ And, although one cannot assert $p \vee q$, while at the same time denying both $p$ and $q$, one can assert $(p \vee q)$ while denying $p$ and $q$. In other words universal modal can get rid of an MF effect, thus yielding an implicature that would be unavailable in their absence.

We can also see that existential modals do not have the power of universal modals.

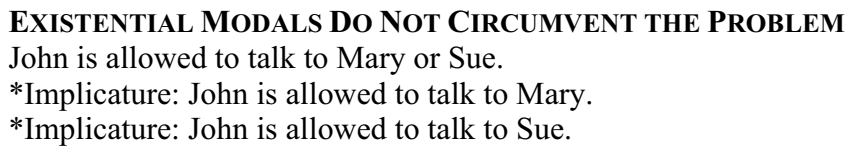

The reason for this is plain. It is contradictory to assert that John is allowed to talk to Mary or Sue and to simultaneously assert both that he is not allowed to talk to Mary and that he is not allowed to talk to Sue.

This general fact about disjunction automatically accounts for the effect in (26-28). Given HG, each of the disjuncts in (26) is stronger than the disjunction. However, the denial of both disjuncts simultaneously contradicts the disjunction, hence yields MF. Embedding under universal quantifiers gets rid of the problem, (27), but embedding under existential quantifiers, (28), does not.

Let's state this again, somewhat more abstractly. Take a sentence $p$ that has one stronger sentence $q$ as an alternative and generates the scalar implicature $\neg q$. Now we can see what is predicted for a sentence such as (26), which, before hearing of HG, we would have mistakenly parsed as $p v q$. Such a sentence, which we will call a Hurford disjunction, although logically equivalent to $p$, does not

\footnotetext{
${ }^{12}$ Additional arguments to those presented here are Sauerland's solution to a much discussed problem for implicature computation in disjunctive sentences (made famous by Gennaro Chierchia), and various proposals for the FC effect referred to below.

${ }^{13}$ To see how we could still generate the implicature that the conjunction false, see Appendix.

${ }^{14} \operatorname{ALT}(\operatorname{Merge}(\mathrm{X}, \mathrm{Y}))=\left\{\operatorname{Merge}\left(\mathrm{X}^{\prime}, \mathrm{Y}^{\prime}\right): \mathrm{X}^{\prime} \in \mathrm{ALT}(\mathrm{X})\right.$ and $\left.\mathrm{Y}^{\prime} \in \mathrm{ALT}(\mathrm{Y})\right\}$
} 
generate $\rightarrow q$ as an implicature. The first step in our account of this fact is the incorporation of $\mathrm{HG}$ with the consequence that the Hurford disjunction should be parsed as $[\operatorname{exh}(p)] v q$, where $\operatorname{exh}(p)$ is equivalent to $p \wedge \neg q$. [exh $(p)] v q$, in contrast to $p$, has two stronger alternatives such that the denial of one, given the basic meaning of the sentence, entails the other (two symmetric alternatives). This fatal symmetry leads to MF, which can be circumvented by a universal modal but not by an existential modal.

\section{Spector (2005)}

We've seen an account for the pattern in (26-28), which is totally independent of the UDM. Spector (2005) suggests that we extend this account to the facts discussed in Section 2.1., thus removing one of our arguments in favor of the UDM. Such an extension would be immediate if the comparatives more than $n$ had the same alternatives as the disjunction $n+1$ or more, which we've looked at in the previous section. (A proposal along this line is also entertained in Russell 2006.)

The consequence is that a sentence such as John has more than 3 children has the same alternatives as John has 4 or more children.

$$
\begin{aligned}
& \mathrm{Alt}(\text { John has more than } 3 \text { children })=\mathrm{Alt}(\text { John has } 4 \text { or more children })= \\
& \{\text { John has exactly } 4 \text { children, John has more than } 4 \text { children. }\}
\end{aligned}
$$

In other words, the sentence has two alternatives which are logically stronger, but they are symmetric, and any attempt to derive a Scalar Implicature leads to a contradiction. This contradiction, as we've already seen, is eliminated by universal modals but not by existentials.

\section{Arguments for Density}

This seems like an interesting proposal. However, it should be clear that it does not eliminate all of our arguments for density. Even if symmetry can account for MF in comparatives (the pattern in 2.1.), it does not extend to MF in negative degree constructions (the pattern in 2.2.). So, if density is still needed for the pattern in 2.2., it is not at all clear that there is an advantage to an account in terms of symmetry for 2.1 .

Furthermore, there seem to be two problems for the extension of the symmetry account to comparatives, which the UDM account does not suffer from, both of which relate to the crucial assumption that the symmetry account builds on, namely (35). ${ }^{15}$ The first problem is conceptual. At the moment, the assumption in (35) is a pure stipulation. In Section 4, we derived the symmetric alternatives for a Hurford disjunction from independently motivated assumption,

\footnotetext{
${ }^{15}$ If the arguments developed by Rick Nouwen in an abstract accepted to the next $S u B$ Conference $(\mathrm{SuB} \mathrm{12})$ are successful, they provide an extremely strong case for the density account.
} 
namely HG and independent considerations pertaining to the implicatures of disjunction (see note 12). However, the extension to comparatives is unmotivated. 16

This is a serious problem. As is well known, one can derive almost everything one wants to within a theory of Scalar Implicatures, if one has total freedom in stipulating alternatives for various constructions. This problem does not arise for the density account outlined in Section 2.1., which is based on independently motivated assumptions about alternatives, namely that degree expressions (e.g. number words) form a Horn scale.

The second problem for a symmetry account is empirical. There seems to be evidence for a difference between Hurford disjunctions and comparatives, which argues that the symmetric alternatives in (35) are correct for Hurford disjunctions but not for comparatives. Consider the oddness of the sequence of sentences in (36). The source of the oddness is the third sentence, which seems to contradict the second one.

(36) You are allowed to smoke 6 or more cigarettes. I am luckier, I am allowed to smoke 7 or more. \#More specifically, I am allowed to smoke 7 cigarettes but not more than 7 .

The explanation for this contradiction follows from the fact that a sentence of the form $\diamond(p \vee q)$ licenses the inference of $\diamond(p)$, and of $\diamond(q)$. The source of these inferences - aka a Free Choice effect (FC) - has been controversial for a while, but recent work has presented evidence that they should follow as scalar implicatures - FC Implicatures - derivable from the symmetric alternatives of disjunction. (See Alonso-Ovalle 2006, Eckardt 2007, Kratzer and Shimoyama 2002, Fox 2007, and Klinedinst 2006.)

Consider now the fact that comparative constructions do not lead to the same oddity:

(37) You are allowed to smoke more than 5 cigarettes. I am luckier, I am allowed to smoke more than 6. More specifically, I am allowed to smoke 7 cigarettes but not more than 7 .

This shows that comparative construction do not yield the same FC effect thus arguing against the extension of the symmetry assumption to comparatives, i.e., against (35). This argument is supported by the contrast in (38), which, for reasons of space, I will have to let the readers interpret on their own.

(38) a. You're only required to read 4 or MORE books. I.e., you're not required to read more than 4 . \#To be more precise, you're required to read exactly 4 (i.e., you're not allowed to read 5)

\footnotetext{
${ }^{16}$ One might attempt to derive the alternatives from considerations of complexity, Katzir (2007). But see F\&H for arguments against such a move.
} 
b. You're only required to read more than THREE books. I.e., you're not required to read more than 4 . To be more precise, you're required to read exactly 4 (i.e., you're not allowed to read 5)

My tentative conclusion is that, although Hurford disjunctions and comparatives have similar implicatures, the source of these implicatures is at least partially different. Both constructions lead to MF unless they are embedded under universal quantifiers. The source of MF however is different. In Hurford disjunctions, MF results from a symmetric set of alternatives, i.e. at least two stronger alternatives such that the denial of one entails the other (given the basic meaning of the sentence). Comparative constructions, however, don't have symmetric alternatives, hence no FC implicature. The explanation of MF in comparative constructions is instead the same explanation that we've provided for negative islands for degree questions and definite descriptions, namely the UDM.

\section{A Broader Generalization 17}

We seem to be forced to group our three constructions in to two different categories. Comparative constructions and negated degree expressions involve MF due to the application of $\mathrm{Max}_{\text {inf }}$ to an $\mathrm{N}$-open property, which cannot have a most informative degree in its extension. Hurford disjunction also lead to MF, but that is due, not to an $\mathrm{N}$-open property, but rather to two symmetric alternatives which cannot be simultaneously excluded.

This grouping raises an obvious question. We've seen that the three constructions, although grouped differently, exhibit an almost identical empirical pattern. Are we, then, missing an important generalization? Before addressing this question, we should eliminate superficial differences. When discussing comparatives and negative degree questions, MF was linked to properties that do not have a maximally informative member in their extension. When we discussed Hurford disjunctions, we did not talk about properties, but about sets of propositions that couldn't be excluded consistently with a given proposition: the relevant disjunction.

However, the discussion of comparatives and negative degree questions can be easily restated in the terms used to discuss Hurford disjunctions. ${ }^{18}$ To see this, we will modify Max $_{\text {inf }}$ in (17) so that it makes reference to sets of alternatives rather than properties. Our lexical entries in (18) will change accordingly.

$$
\begin{aligned}
\operatorname{MAX}_{\text {inf }}\left(\mathrm{A}_{<\mathrm{st}, \mathrm{t}}\right)(\mathrm{w})= & \text { the } \mathrm{p} \in \mathrm{A}, \text { s.t., } \mathrm{p}(\mathrm{w})=1 \text { and } \\
& \forall \mathrm{q} \in \mathrm{A}(\mathrm{q}(\mathrm{w})=1 \rightarrow \mathrm{p} \text { entails } \mathrm{q})
\end{aligned}
$$

\section{Lexical Entries}

\footnotetext{
${ }^{17}$ The discussion in this section was simplified (relative to the SALT handout) as a result of a conversation with Márta Abrusán for which I am very grateful.

${ }^{18}$ The converse is not true, since the alternatives for the relevant disjunctions can not be derived by application of the same property to different individuals (see note 5).
} 
a. $\llbracket \operatorname{exh} \rrbracket(\mathrm{A})(\mathrm{p})(\mathrm{w}) \Leftrightarrow \mathrm{p}=\mathrm{MAX}_{\mathrm{inf}}\left(\mathrm{A}_{<\mathrm{st}, \mathrm{t}}\right)(\mathrm{w})$

b. $\llbracket$ only $\rrbracket(A)(p)(w) \Leftrightarrow p=\operatorname{MAX}_{\text {inf }}\left(\mathrm{A}_{<\mathrm{st}, \mathrm{t}}\right)(\mathrm{w})$

c. $\llbracket ? \rrbracket\left(\varphi_{\alpha, \mathrm{st}}\right)=\lambda \mathrm{w}: \exists \mathrm{p}\left[\mathrm{p}=\operatorname{MAX}_{\text {inf }}\left(\left\{\varphi(\mathrm{x}): \mathrm{x} \in \mathrm{D}_{\alpha}\right\}\right)(\mathrm{w})\right] .\left\{\varphi(\mathrm{x}): \mathrm{x} \in \mathrm{D}_{\alpha}\right\}$

d. $\llbracket$ the $\rrbracket(\varphi)(w)=$ the $\mathrm{x} \in \mathrm{D}_{\alpha}$, s.t. $\left.\varphi(\mathrm{x})=\operatorname{MAX}_{\text {inf }}\left(\left\{\varphi(\mathrm{x}): \mathrm{x} \in \mathrm{D}_{\alpha}\right\}\right)(\mathrm{w})\right]$

So now back to our question: are we missing an important generalization? I will claim that we're not. Specifically, I will claim that we are in the situation we should be in. Given the modification of Max $_{\text {inf }}$, the CIM (in 16) should now be restated as the following constraint:

(41) Constraint on Set Maximization (CSM): sets of propositions that don't have a most informative member cannot be maximized by MAX $_{\text {inf. }}$.

We continue to take this constraint to be self-evident, and we're glad to observe that all cases of MF discussed in this paper are still cases where the constraint is violated. It is indeed a heterogeneous class, but we should not be bothered by this fact: it is an unavoidable fact of logic. What is important is that once we have a violation of the constraint, the pattern of obviation we've identified will continue to be the result of rather trivial logical properties.

To illustrate this, consider a third possible source for MF, namely an empirical/contextual source, rather than a logical source. Assume that there is a consistent set of rules and regulations that specify the requirement for graduation at a certain doctorate program. Consider now the utterances in (42-43)

(42) According to the rules, every student in the program has to have 3 professors on his committee.

a. \#John's committee is consistent with the rules, and Mary is the only professor on his committee.

b. Mary is the only professor that John is required (by the rules) to have on his committee.

c. \#Mary is the only professor that John is allowed (by the rules) to have on his committee.

(43) I know that John's committee is consistent with the rules, but I don't know

a. \# which professor he has on his committee?

b. which professor John is required (by the rules) to have on his committee?

c. \#which professor John is allowed (by the rules) to have on his committee? ${ }^{19}$

Density and Symmetry are irrelevant for the explanation of this pattern. Yet, it is the same pattern we've seen throughout this paper. Clearly, we need a broader generalization, namely that when a proposition cannot be the most informative

\footnotetext{
${ }^{19}$ What is crucial for (43) is the uniqueness presupposition of singular which questions, which follows in Dayal (2006) from the requirement that there be a most informative member in the Karttunen denotation, (40c).
} 
among a set of alternatives, when we encounter MF, the problem can disappear by introducing a universal modal but an existential modal is of no help.

Let $\mathrm{p}$ be a proposition and $\mathrm{A}$ a set of propositions (possibly infinite). We will say that $p$ is non-exhustifiable given $A$ : $N E(p, A)$ if the denial of all alternatives in $A$ that are not entailed by $p$ is inconsistent with $p$.

$$
\begin{aligned}
\mathrm{NE}(\mathrm{p}, \mathrm{A}) & \Leftrightarrow \mathrm{p} \cap \bigcap\{\neg \mathrm{q}: \mathrm{q} \in \mathrm{A} \& \neg(\mathrm{p} \Rightarrow \mathrm{q})\}]=\varnothing . \\
& \Leftrightarrow \forall \operatorname{wMax}_{\inf }(\mathrm{A})(\mathrm{w}) \neq \mathrm{p}
\end{aligned}
$$

We will see that the cases we've discussed receive a uniform explanation. All the Basic-Effect cases involve linguistic expressions that are unacceptable (or implicatures that are unavailable) because they would involve a contradictory statement, namely a statement that $p$ is the most informative true member in a set A, s.t. $\mathrm{NE}(\mathrm{p}, \mathrm{A})$ is true. Obviation by universal but not by existential quantification will turn out to be a trivial logical property.

Our explanation of the Basic Effect in a Hurford disjunction, $\mathrm{p}$ (Section 4), was based on the independently motivated assumption that the set of alternatives, A, contains two symmetric alternatives, from which it follows that $\mathrm{NE}(\mathrm{p}, \mathrm{A})$ holds. Our explanation of the Basic Effect in comparatives and degree questions was based on the logical traits of $\mathrm{N}$-open properties, but could now be recast in terms of a non-exhaustifiable proposition, once we point out the obvious relation between these two ways of talking, namely that if $\varphi$ is $\mathrm{N}$-open, then $\forall \mathrm{xNE}(\varphi(\mathrm{x})$, Range $(\varphi))$ holds. We derive all of our results as follows.

(45) Basic Consequence: If $\forall x N E(\varphi(x)$, Range $(\varphi))$ and $\mathrm{NE}(\mathrm{p}, \mathrm{A})$, then sentences that express the following should be contradictory, hence unacceptable.
a. $\quad \operatorname{exh} \rrbracket(A)(p)$
b. $\llbracket$ only $\rrbracket(A)(p)$
c. $\llbracket ? \rrbracket(\varphi)$
d. $\llbracket$ the $\rrbracket(\varphi)(w)$

The fact that universal modals circumvent the problem but existential modals cannot is an automatic consequence, as well:

A universal modal eliminates Non-exhaustifiability:

If $p$ is consistent, $\mathrm{NE}(\mathrm{p},(\mathrm{A}))$ does not hold (even if $\mathrm{NE}(\mathrm{p}, \mathrm{A})$ holds)

$$
\text { (where } \mathrm{A}=\{\mathrm{p}: \mathrm{p} \in \mathrm{A})\} \text { ) }
$$

Proof: Let the modal base for $\quad$ in $\mathrm{w}^{0}$ be $\{\mathrm{w}: \mathrm{p}(\mathrm{w})=1\}$. It is easy to see that for every $q \in A$, s.t., $q$ is not entailed by $p$, there is a world in the modal base that falsifies $q$.

(47) Consequence for universal modals: A universal modal eliminates Nonexhaustifiability; hence even if $\forall \mathrm{xNE}(\varphi(\mathrm{x})$, Range $(\varphi))$ or $\mathrm{NE}(\mathrm{p}, \mathrm{A})$, then 
sentences that express the following should be non-contradictory, hence acceptable:
a. $\llbracket \operatorname{exh} \rrbracket(A)(\mathrm{p})$

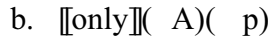
c. $\llbracket ? \rrbracket(\varphi)$
d. the $\rrbracket(\varphi)(w)$

An existential modal does not eliminate Non-Exhaustifiability: if $\mathrm{NE}(\mathrm{p}, \mathrm{A})$ holds, so does $\mathrm{NE}(\diamond \mathrm{p}, \diamond \mathrm{A}) \quad($ where $\diamond \mathrm{A}=\{\diamond \mathrm{p}: \mathrm{p} \in \mathrm{A})\})$

Proof: Assume otherwise, and let MB be the modal base that satisfies $\diamond \mathrm{p}$ but does not satisfy any of the propositions in $\diamond \mathrm{A}$ not entailed by $\diamond \mathrm{p}$ (i.e. any of the proposition $\diamond \mathrm{q}$ in $\diamond \mathrm{A}$ such that $\mathrm{q}$ is not entailed by $\mathrm{p}$ ) . Since $\diamond p$ is true, $\exists w \in M B$, s.t. $p(w)=1, w_{p}$. For each $q \in A$, such that $p$ does not entail $\mathrm{q}, \mathrm{q}\left(\mathrm{w}_{\mathrm{p}}\right)=0$ since $[\neg \nabla \mathrm{q}](\mathrm{w})=1$. But this means that all non-entailed members of A could be denied consistently, contrary to assumption.

(49) Consequence for existential modals: An existential modal does not eliminate Non-exhaustifiability; hence if $\forall x N E(\varphi(x)$, Range $(\varphi))$ or $\mathrm{NE}(\mathrm{p}, \mathrm{A})$ holds, sentences that express the following should be contradictory, hence unacceptable:
a. $\llbracket \operatorname{exh} \rrbracket(\mathrm{A})(\mathrm{p})$

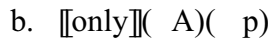

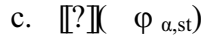
d. the $\rrbracket(\varphi)(w)$

\section{Negative Islands and Maximization Failure}

The observation made in the previous section provides us with a signature of MF. To see how this could be useful, consider the fact that negative islands restrict other constructions besides degree questions. We would like to know whether the various restrictions should all follow as MF effects.

Consider from this perspective the following contrast:
a. *(I know) how you did not [behave t].
b. (I know) how you are not allowed to [behave t].
c. *(I know) how you are not required to [behave $\mathrm{t}$ ].
a. *(I know) why you did not [behave well t].
b. *(I know) why you are not allowed to [behave well $\mathrm{t}$ ].
c. *(I know) how you are not required to [behave well $\mathrm{t}$ ].

This contrast provides us with evidence that negative islands in manner questions should follow as MF effects, whereas negative islands in why-questions should 
receive an independent account. I have nothing to say about the account of negative islands in why-questions. ${ }^{20} \mathrm{I}$ also don't have anything particularly interesting to say about the possible sources of the MF effect in manner questions, but there the strategy is obvious: make some assumption about the domain of manners that would derive the basic effect, and see how reasonable that assumption might be. The consequences for universal and existential modals will follow automatically from what we've seen in Section 7. See Abrusán (2007) where this strategy is pursued with many additional interesting consequences. ${ }^{21}$

Another case worth exploring is one discovered in Spector (2007), where the following paradigm is introduced.

(52) a. \#I know which books Jack did not read, the Russian or the French books. (Bad under narrow scope for disjunction, hence ends up pragmatically odd.)

b. I know which books we are not allowed to read, the Russian or the French books. (Good under narrow scope for disjunction.)

c. \#I know which books we are not required to read, the Russian or The French books. (Bad under narrow scope for disjunction, hence ends up pragmatically odd.)

If the semantics for the relevant questions is such that (52a) is a case of MF, $(52 \mathrm{~b}, \mathrm{c})$ would follow automatically. The desideratum is thus quite clear. Whether it can be achieved is something I am very eager to find out.

\section{Appendix $^{22}$}

The discussion of only and the operator relevant for scalar implicatures, exh, was based on a problematic lexical entry for these items, (40a,b) (see notes 6 and 13). The goal of this appendix is to show that this simplification does not affect the outcome. To understand the problem, consider what happens in simple disjunctive sentences, such as (53). These sentences generate the familiar scalar implicature that the conjunctive alternative is false, even though exh, as defined in (40a), would yield a contradiction (given the symmetric alternatives).

$$
\begin{aligned}
& \text { John talked to Mary or Sue. } \quad \quad M \vee S \\
& \text { Alternatives: } M, S, M \wedge S \\
& \text { implicature: } \neg(M \wedge S)
\end{aligned}
$$

\footnotetext{
${ }^{20} \mathrm{But}$ see Ko (2005) and references therein for arguments that the properties of $w h y$-questions are quite unique.

${ }^{21}$ In my SALT handout, I suggested that manners are not closed under sum formation, and that MF follows with the help of the extra assumption that any sentence $S$ that can be modified by a manner $\mathrm{M}$ (with the result annotated as $\mathrm{S} \wedge \mathrm{M}$ ) there have to be at least two manners $\mathrm{M}$ such that $\mathrm{S} \wedge \mathrm{M}$ is false.

${ }^{22}$ Thanks to Kai von Fintel and Benjamin Spector for discussions of the issues presented in the Appendix.
} 
This problem was noted by Groenendijk and Stokhof (1984) in a related context, and extends, as they show, to various sentences with only. (See Fox 2007 for a review.)

In order to deal with this problem, I will assume the lexical entries proposed in Fox (2007): ${ }^{23}$

$$
\begin{aligned}
& \text { a. } \quad \text { oonly } \rrbracket\left(\mathrm{A}_{<\mathrm{st}, \mathrm{\triangleright}}\right)\left(\mathrm{p}_{\mathrm{st}}\right) \Leftrightarrow \llbracket \operatorname{exh} \rrbracket\left(\mathrm{A}_{<\mathrm{st}, \mathrm{\downarrow}}\right)\left(\mathrm{p}_{\mathrm{st}}\right)(\mathrm{w}) \\
& \Leftrightarrow \mathrm{p}(\mathrm{w}) \& \forall \mathrm{q} \in \mathrm{I}-\mathrm{E}(\mathrm{p}, \mathrm{A}) \rightarrow \neg \mathrm{q}(\mathrm{w}) \\
& \left.\mathrm{I}-\mathrm{E}(\mathrm{p}, \mathrm{A})=\cap\left\{\mathrm{A}^{\prime} \subseteq \mathrm{A}: \mathrm{A}^{\prime} \text { is a maximal set in } \mathrm{A} \text {, s.t., } \mathrm{A}^{\prime}\right\urcorner \cup\{\mathrm{p}\} \text { is consistent }\right\} \\
& \mathrm{A}\urcorner=\{\neg \mathrm{p}: \mathrm{p} \in \mathrm{A}\}
\end{aligned}
$$

The disjunction in (53) has three alternatives, all of which are stronger than (53). Under (40a), all of these stronger alternatives would have to be excluded and the result would be inconsistent. By (54), however, the only excluded alternatives are the "innocently excludable" alternatives [IE((53), ALT), where ALT is the set of the three alternatives]. To see if a proposition $\mathrm{q}$ is innocently excludable, we must look at every maximal set of alternative propositions such that its exclusion is consistent with (53), namely the two sets $\{\mathrm{M}, \mathrm{M} \wedge \mathrm{S}\}$, and $\{\mathrm{S}, \mathrm{M} \wedge \mathrm{S}\}$. The innocently excludable propositions are those that are in every such set. $\operatorname{IE}((53)$, ALT), thus, contains just one proposition, namely $\mathrm{M} \wedge \mathrm{S}$.

Excluding the set of innocently excludable propositions is always consistent with the prejacent (the propositional argument of only or exh). Hence, there can be no contradiction that results from the application of only or exh to a consistent proposition. But still we can derive the lack of an implicature in certain environments if we can show that the set of alternatives has no innocently excludable members. We might, therefore, give such cases the MF-label and claim that sentences with only or exh will be unacceptable (due to the vacuity of the operator, see Chierchia 2007). This will be needed to rule out all of the unacceptable sentences with only that we discussed, starting with (5b).

\section{THE BASIC EFFECT:}

MF Holds if IE(A,p) $=\varnothing$

If $\operatorname{IE}(A, p)=\varnothing$, then $\operatorname{EXH}(A)(p)=\operatorname{ONLY}(A)(p)=p(*$ by definition* $)$.

(56) Universal Modals Circumvent the Problem

If $p$ is consistent, and $\exists q \in A$, such that $p$ does not entail $q$

$$
\operatorname{IE}(\mathrm{p}, \mathrm{A}) \neq \varnothing \quad \text { (where } \mathrm{A}=\{\mathrm{p}: \mathrm{p} \in \mathrm{A})\} \text { ) }
$$

Proof: If we take $\{\mathrm{w}: \mathrm{p}(\mathrm{w})=1\}$ to be the modal base, every proposition in $\mathrm{X}=\{\mathrm{q} \in \mathrm{A}: \mathrm{q}$ is not entailed by $\mathrm{p}\}$ is false. There is no larger set of propositions $\mathrm{A}^{\prime} \subseteq \mathrm{A}$ such that its exclusion is consistent with $\mathrm{p}$. Hence, $\operatorname{IE}(\mathrm{p}, \mathrm{A})=\mathrm{X} \neq \varnothing$.

\footnotetext{
${ }^{23}$ For an alternative perspective which keeps to our basic lexical entries with the aid of certain syntactic assumptions, see Katzir (to appear), Kratzer (2005), and Spector $(2005,2007)$.
} 
EXISTENTIAL MODALS Do Not

If $\operatorname{IE}(\mathrm{A}, \mathrm{p})=\varnothing, \operatorname{IE}((\diamond \mathrm{A}),(\diamond \mathrm{p}))=\varnothing \quad$ (where $\diamond \mathrm{A}=\{\diamond \mathrm{p}: \mathrm{p} \in \mathrm{A})\})$

Proof:

Lemma: $\forall \mathrm{B} \subseteq \mathrm{A}$

$[(\{\mathrm{p}\} \cup\{\neg \mathrm{q}: \mathrm{q} \in \mathrm{B}\}$ is consistent $) \Leftrightarrow(\{\diamond \mathrm{p}\} \cup\{\neg \vee \mathrm{q}: \mathrm{q} \in \mathrm{B}\}$ is consistent $)]$

Proof:

Let $\mathrm{B} \subseteq \mathrm{A}$

$\Rightarrow$

Let $\mathrm{w}$ be a world that satisfies every proposition in $\{\mathrm{p}\} \cup\{\neg \mathrm{q}: \mathrm{q} \in \mathrm{B}\}$

If the modal base for $\diamond$ in $\mathrm{w}^{\prime}$ is $\{\mathrm{w}\}$, then $(\diamond \mathrm{p}\} \cup\{\neg \diamond \mathrm{q}: \mathrm{q} \in \mathrm{B}\}$ are all true.

$\Leftarrow$

Let MB be the modal base that satisfies every proposition in $(\diamond \mathrm{p}\} \cup\{\neg \vee \mathrm{q}: \mathrm{q} \in \mathrm{B}\}$. Since $\diamond \mathrm{p}$, there is a world $\mathrm{w} \in \mathrm{MB}$, s.t. $\mathrm{p}(\mathrm{w})=1$. It is easy to see that $w$ satisfies every proposition in $\{\neg q: q \in B\}$.

It is now easy to see that $\operatorname{IE}(\mathrm{P}, \mathrm{A})=\operatorname{IE}((\diamond \mathrm{A}),(\diamond \mathrm{p}))$

This will be our explanation for the lack of obviation by existential quantifiers.

\section{References}

Abrusán, Márta: 2007, Contradiction and Grammar: The Case of Weak Islands, Doctoral Dissertation, MIT.

Alonso-Ovalle, Luis: 2006, Disjunction in Alternative Semantics, Doctoral Dissertation, University of Massachusetts.

Chierchia, Gennaro: 2007, 'Polarity Sensitivity: The Role of Higher Order Implicatures', paper presented at SALT XVII.

Chierchia, Gennaro, Danny Fox, and Benjamin Spector: in progress, Embedded Implicatures and the Relationship between Semantics and Pragmatics, Ms.

Dayal, Veneeta: 1996, Locality in Wh-Quantification, Dordrecht: Kluwer.

Eckardt, Regine: 2007, 'Licensing or', in Presupposition and Implicature in Compositional Semantics, eds. Uli Sauerland and Penka Stateva, 34-70. New York: Palgrave Macmillan.

Fox, Danny: 2004, 'Only a little bit more', Class 5 of Implicatures and Exhaustivity. Handouts from a class taught at USC. http://web.mit.edu/linguistics/people/faculty/fox/class 5.pdf.

Fox, Danny: 2007, 'Free Choice Disjunction and the Theory of Scalar Implicatures', in Presupposition and Implicature in Compositional Semantics, eds. Uli Sauerland and Penka Stateva, 71-120. New York: Palgrave Macmillan. 
Fox, Danny, and Martin Hackl: 2006, 'The Universal Density of Measurement', Linguistics and Philosophy 29 537-586.

Gazdar, Gerald: 1979, Pragmatics: Implicature, Presupposition and Logical Form. New York: Academic Press.

Groenendijk, Jeroen., and Martin Stokhof: 1984, Studies on the Semantics of Questions and the Pragmatics of Answers, University of Amsterdam.

Hurford, James R.: 1974, 'Exclusive or Inclusive Disjunction', Foundation of Language 11:409-411.

Katzir, Roni. 2007, Structurally-Defined Alternatives, Ms. MIT.

Keshet, Ezra. 2007. 'Scalar Implicatures with Alternative Semantics', in Proceedings of SALT XVI, CLC Publications, Cornell University, Ithaca.

Klinedinst, Nathan: 2006, Plurality and Possibility, Doctoral Dissertation, UCLA.

Ko, Heejeong: 2005, 'Syntax of Why-in-situ: Merge into [Spec,CP] in the Overt Syntax', Natural Language and Linguistic Theory 23:867-916.

Kratzer, Angelika and Junko Shimoyama: 2002, Indeterminate Pronouns: The View from Japanese, Tokyo.

Kratzer, Angelika: 2005, LSA Class Notes.

Nouwen, Rick: 2007, 'Upperbound no more', abstract accepted for $S u B 12$.

Russell, Benjamin: 2006, 'Against Grammatical Computation of Scalar Implicatures', Journal of Semantics 23:361 - 382.

Sauerland, Uli: 2004, 'Scalar Implicatures in Complex Sentences', Linguistics and Philosophy 27:367-391.

Sauerland, Uli: 2005, 'The Epistemic Step', paper presented at Experimental Pragmatics, Cambridge University, Cambridge, UK. .

Sevi, Aldo: 2005, Exhaustivity: a Semantic Account of Scalar Implicatures, Doctoral Dissertation, Tel-Aviv University.

Simons, Mandy: 2000, Issues in the Semantics and Pragmatics of Disjunction. New York and London: Garland Pub.

Singh, Raj: 2006, 'Eager for Distinctness', in Eleventh ESSLLI Student Session eds. Jenneke Huitink and Sophia Katrenko, 76-89.

Spector, Benjamin: 2005, Aspects de la Pragmatique des Opérateurs Logiques, Doctoral Dissertation, Université Paris 7.

Spector, Benjamin: 2007, 'Modalized Questions and Exhaustivity', Paper presented at $S A L T X V I I$. 